\title{
Power System Analysis Toolbox (PSAT) Circuit Design of Nigeria 330Kv 10 Generators 28 Bus Power Network for Transient Stability Simulation
}

\author{
Isdore Onyema Akwukwaegbu*1, Chisom Patrick Mbachu ${ }^{2}$, Nsan-Awaji Peterson Ene-Nte ${ }^{2}$ \\ ${ }^{l}$ Department of Electrical /Electronic Engineering, School of Engineering, Federal University of Technology, Owerri, Nigeria. \\ ${ }^{2}$ Department of Electrical /Electronic Engineering, Federal University of Technology, Owerri, Nigeria. \\ DOI: 10.31364/SCIRJ/v9.i01.2021.P0121838 \\ http://dx.doi.org/10.31364/SCIRJ/v9.i01.2021.P0121838
}

\begin{abstract}
Nigeria 330kV 28-bus network is continuously subjected to the greatest stress that can possibly emanate from a complete shutdown of a power plant or even a blackout of a whole area or excessive over currents or voltages which, depending upon their severity can cause extensive damage. The main causes of momentary excessive voltages and currents in power system due to transients include lightning, switching, short circuits and resonance conditions. Transient stability analysis is carried out on Nigeria 330kV 28 -bus power network, consisting of 28 nodes, 10 generators, 18 load (PQ) buses, 16 transformers, 12,426MW grid capacity and 5,988km grid transmission lines to access the steady state voltage stability using MATLAB/ SIMULINK power system analysis toolbox (PSAT) program. The generator connected at bus no. 5 (Sapele PS) is shut down and the transient stability effect and impact on the 28-bus power network are analyzed. The starting time of the outage is $\mathbf{0 . 0 0 0 1}$ second and transient phenomenon lasts in the $\mathbf{2 8}$-bus power network for a period of time ranging from 0.6 to 0.9 seconds. The transient stability analysis performed for 10 generators, 28-bus power network for various 3-phase fault locations and 3-phase fault clearing time showed that the network is stable in 0.80 seconds, critically stable in 0.815 seconds and unstable in 0.9 seconds.
\end{abstract}

Keywords: Nigeria 330kV 28-bus Power Network, Transient stability analysis, MATLAB/ SIMULINK Power System Toolbox (PSAT)

\section{Introduction}

The propensity of a power system to create restoring forces greater than or equal to the disturbing forces and at same time, able to hold the forces that tend to keep the system in synchronism in order to maintain the state of equilibrium is known as stability. If the forces tending to hold machines in synchronism with one another are sufficient to overcome the disturbing forces, the system is said to remain stable (stay in synchronism).

The power system stability problem deals with the behavior of the synchronous machines after they have been perturbed or disturbed. If the perturbation does not involve any net change in the power, the machines should return to their original state. If an unbalance between the supply and demand is created by a change in load, in generation, or in network conditions, a new operating state is necessary. In any case, all interconnected synchronous machines should remain in synchronism if the system is stable, i.e., they should all remain operating in parallel and at the same speed [1]. While the stability of synchronous machines and tie lines is the most important and common problems, other stability problems may exist, particularly in power systems having appreciable capacitances. In such cases, arrangements must be made to avoid excessive voltages during light load conditions, to avoid damage to equipment, and to prevent self-excitation of machines.

Transient stability studies deal with the effects of large, sudden disturbances such as the occurrence of a fault, the sudden outage of a line or the sudden application or removal of loads $[2,3]$. Transient stability studies are necessary to ensure that the system can withstand the transient condition following a major disturbance [4]. Frequently, such studies are conducted when new generating and transmitting facilities are planned. The studies are helpful in determining such things as the nature of the relaying system needed, critical clearing time of circuit breakers, voltage level of, and transfer capability between systems [5,6]. Transient stability implies the assessment of a power system's competence to withstand large disturbances, and to survive transition to a normal operating condition. These disturbances can appear to be faults such as: a short circuit on a transmission line, loss of a generator, loss of a load, gain of load or loss of a portion of transmission network $[7,8]$.

Large number of simulations is carried out regularly during stages to gain knowledge of this system. Yet, even a welldesigned and normally operated system may face the threat of transient instability of 10 generators, 28-bus Nigeria power network is performed for various 3-phase fault locations and 3phase fault clearing time in 0.6 seconds, 0.7 seconds, 0.8 seconds, 0.815 seconds and 0.9 seconds respectively.

*Corresponding Author: Isdore Onyema Akwukwaegbu, Department of Electrical /Electronic Engineering, Federal University of Technology, PWWw.scirj.org

1526, Owerri Imo state, Nigeria. Email: isdoreonyema@gmaifferp21, Scientific Research Journal

http://dx.doi.org/10.31364/SCIRJ/v9.i01.2021.P0121838

This publication is licensed under Creative Commons Attribution CC BY. 
The simplified assumptions made in writing 10 generators equations are presented as follows [6]:

- Every single synchronous machine is represented by a constant voltage source behind the direct axis transient reactance. This representation neglects the effect of saliency and assumes constant flux linkages.

- The governor's actions are neglected and the input powers are assumed to remain constant during the entire period of simulation.

- Using the pre-fault bus voltages, all loads are converted to equivalent admittances to ground and are assumed to remain constant.

- Damping or asynchronous powers are ignored.

- The mechanical rotor angle of each machine coincides with the angle of the voltage behind the machine reactance.

- Machines belonging to the same station swing together and are said to be coherent. A group of coherent machines is represented by one equivalent machine.

\section{Mathematical Formulation for $\mathbf{1 0}$ Generators, 28-Bus Nigeria Power Network}

The foremost step to take in the analysis of transient stability is to solve the initial load flow and thus, determine the initial bus voltage magnitudes and phase angles. The machine currents prior to disturbance are calculated from:

$$
I_{i}=\frac{s_{i}^{*}}{V_{i}^{*}}=\frac{P_{i}-j Q_{i}}{V_{i}^{*}} \quad i=1,2, \ldots, m
$$

Where $m$ is the number of generators; $\mathrm{V}_{\mathrm{i}}$ is the terminal voltage of the $i^{\text {th }}$ generator; $\mathrm{P}_{\mathrm{i}}$ and $\mathrm{Q}_{\mathrm{i}}$ are the generator real and reactive powers. All unknown values are determined from the initial power flow solution. The generator armature resistances are usually neglected and the voltages behind the transient reactances are then obtained.

$$
E_{i}^{\prime}=V_{i}+j X_{d}^{\prime} I_{i}
$$

Next, all loads are converted to equivalent admittances by using the relation

$$
y_{i 0}=\frac{S_{i}^{*}}{\left|V_{i}\right|^{2}}=\frac{P_{i}-j Q_{i}}{\left|V_{i}\right|^{2}}
$$

To include voltages behind transient reactances, $m$ buses are added to $n$-bus power system network. The equivalent network with all loads converted to admittances is shown in figure 1.

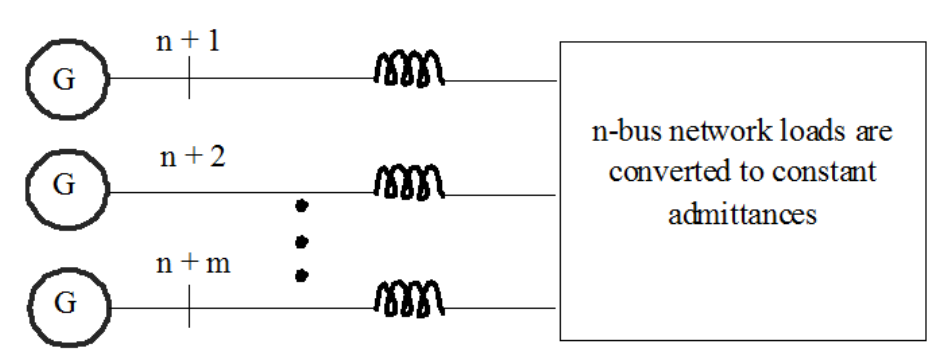

Nodes $n+1, n+2, \ldots, n+m$ are the internal machine buses, i.e., the buses behind the transient reactances. The node voltage equation with node 0 as reference for this network is

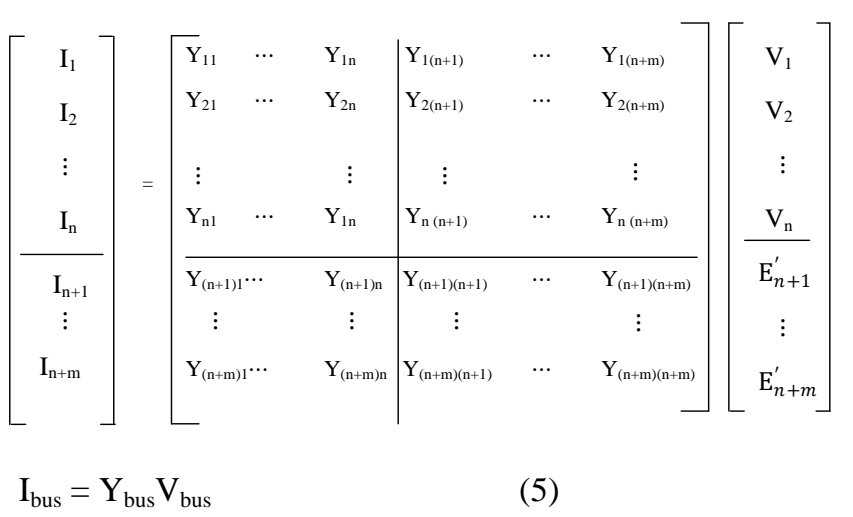

Where $I_{\text {bus }}$ is the injected bus currents and $V_{\text {bus }}$ is the vector of bus voltages measured from the reference node. The diagonal elements of the bus admittance matrix are the sum of admittances connected to it, and the off-diagonal elements are equal to the negative of the admittance between the nodes. Additional nodes are added to include the machine voltages behind transient reactances; and diagonal elements are modified to include the load admittances. To make the analysis simpler, the generator internal nodes are maintained, while other nodes are eliminated using the Kron reduction formula [9]. To eliminate the load buses, the bus admittances matrix in equation (4) is partitioned in a way that the $n$ buses to be removed are represented in the upper $\mathrm{n}$ rows. Since no current enters or leaves the load buses, currents in the n rows are zero (0). The generator currents are denoted by the vector $I_{m}$, the generator and load voltages are represented by the vectors $E_{m}^{\prime}$ and $V_{n}$ respectively. Equation (4), in sub matrix form, becomes [6]

$\left[\begin{array}{c}0 \\ I_{m}\end{array}\right]=\left[\begin{array}{cc}Y_{n n} & Y_{n m} \\ Y_{n m}^{t} & Y_{m m}\end{array}\right]\left[\begin{array}{c}V_{n} \\ E_{m}^{\prime}\end{array}\right]$

The voltage vector $\mathrm{V}_{\mathrm{n}}$ may be eliminated by substitution as follows:

$0=Y_{n n} V_{n}+Y_{n m} E_{m}^{\prime}$

$I_{m}=Y_{n m}^{t} V_{n}+Y_{m m} E_{m}^{\prime}$

From equation (7),

$V_{n}=-Y_{n n}^{-1} Y_{n m} E_{m}^{\prime} \square$

Substituting equation (9) into equation (8) would yield

$\mathrm{I}_{\mathrm{m}}=\left[Y_{m m}-Y_{n m}^{t} Y_{n n}^{-1} Y_{n m}\right] E_{m}^{\prime}=Y_{b u s}^{r e d} E_{m}^{\prime}$

The reduced admittance matrix is

$Y_{\text {bus }}^{\text {red }}=Y_{m m}-Y_{n m}^{t} Y_{n n}^{-1} Y_{n m}$

Figure 1: Power system representation for transient stability analysis. 
The reduced bus admittance matrix has the dimensions ( $\mathrm{m} \mathrm{x} \mathrm{m}$ ), where $\mathrm{m}$ is the number of generators.

The electrical power output of each machine can now be expressed in terms of machine's internal voltages as follows:

$S_{e i}^{*}=E_{i}^{* *} I_{i}$

Where:

$I_{i}=\sum_{j=1}^{m} E_{j}^{\prime} Y_{i j} \square$

The voltages and admittances are expressed in polar form as follows:

$E_{i}^{\prime}=\left|E_{i}^{\prime}\right| \angle \delta_{i}$

$Y_{i j}=\left|Y_{i j}\right| \angle \theta_{i j}$

Substituting equation (14) for $\mathrm{I}_{\mathrm{i}}$ in equation (13) results in

$P_{e i}=\sum_{j=1}^{m}\left|E_{i}^{\prime}\right|\left|E_{j}^{\prime}\right|\left|Y_{i j}\right| \cos \left(\theta_{i j}-\delta_{i}+\delta_{j}\right)$

Prior to the disturbance, there is equilibrium between the mechanical power input and the electrical power output as follows:

$P_{m i}=P_{e i}=\sum_{j=1}^{m}\left|E_{i}^{\prime}\right|\left|E_{j}^{\prime}\right|\left|Y_{i j}\right| \cos \left(\theta_{i j}-\delta_{i}+\delta_{j}\right)$

The classical stability study of 10 generators, 28-bus Nigeria power network is based on the application of a three-phase fault. A solid three-phase fault at bus $\mathrm{k}$ in the network results in $\mathrm{V}_{\mathrm{k}}=$ 0 . This simulation is performed by removing the $\mathrm{k}^{\text {th }}$ row and column from the pre-fault bus admittance matrix. The new bus admittance is reduced by eliminating all nodes except the internal generator nodes. A simple assumption is made here: the generator excitation voltages during the fault and pre-fault modes remain constant. The electrical power of the $i^{\text {th }}$ generator in terms of the new reduced bus admittance matrices are obtained from equation (15). The swing equation with the damping neglected for machine $i$ becomes

$\frac{H_{i} d^{2} \delta_{i}}{\pi f_{0} d t^{2}}=P_{m i}-\sum_{j=1}^{m}\left|E_{i}^{\prime}\right|\left|E_{j}^{\prime}\right|\left|Y_{i j}\right| \cos \left(\theta_{i j}-\delta_{i}+\delta_{j}\right)$

Where $Y_{i j}$ are the elements of the faulted-reduced-bus admittance matrix and $\mathrm{H}_{\mathrm{i}}$ is the inertia constant of machine $i$ expressed on the machine rated MVA $\mathrm{S}_{\mathrm{Gi}}$; then $\mathrm{H}_{\mathrm{i}}$ is given by

$H_{i}=\frac{s_{G i} H_{G i}}{s_{B}}$

Expressing the electrical power of the $i^{\text {th }}$ generator by $P_{e}^{f}$ and transforming equation (17) into state variable model yields

$\frac{d \delta_{i}}{d t}=\Delta \omega_{i} \quad i=1,2,3, \cdots, m$

$\frac{d \Delta \omega_{i}}{d t}=\frac{\pi f_{0}}{H_{i}}\left(P_{m}-P_{e}^{f}\right)$

\section{Simulation of $\mathbf{1 0}$ Generators, 28-Bus Nigeria Power Network}

A specialized tool in MATLAB environment is developed using Power System Analysis Toolbox (PSAT) for providing fundamental examination of 10 generators, 28-bus Nigeria power network transient stability analysis. Power System Analysis Toolbox (PSAT) is a Simulink-based open-source library for electric power system analyses and simulations, distributed via General Public License (GPL) [10,11]. It contains the tools for power flow (busbars, lines, two/three winding transformers, slack bus(es), shunt admittances, etc), Continuation Load Flow(CLF) data (power supply/demand bids and limits, generator power reserves and ramping data), small Signal Stability Analysis and Time Domain Simulations. Moreover, line faults and breakers, various load types, machines, controls, OLTC transformers, FACTs and other can be also modeled. User defined device models can be added as well.

For 10 generators, 28-bus Nigeria power network transient stability, there are two state equations for each generator, with initial power angles $\delta_{0}$ and $\Delta \omega_{0 \mathrm{i}}=0$. The program developed in MATLAB is employed to solve the above $2 \mathrm{~m}$ first-order differential equations. When the fault is cleared, which entails the removal of generator bus or any faulty line, the bus admittance matrix is computed over again to reflect the change in the network.

Next, the post-fault reduced bus admittance matrix is evaluated and the post-fault electrical power of the $\mathrm{i}^{\text {th }}$ generator shown by $\mathrm{P}_{\mathrm{i}}^{\mathrm{pf}}$ is readily determined from equation (15). Using the post-fault power $\mathrm{P}_{\mathrm{i}}{ }^{\mathrm{pf}}$, the simulation is allowed to go on, so as to determine the system stability until the plots reveal a definite trend as stability or instability.

The 28-bus power network is the grid of Nigeria power system, consisting of 28 nodes, 10 generators, 18 load (PQ) buses, 16 transformers, $12,426 \mathrm{MW}$ grid capacity and $5,988 \mathrm{Km}$ grid transmission lines. The 28-bus grid network with a total load of 2,468.06MW and 1,851.05Mvar has buses numbered as follows: bus no.1 (slack); bus no.2 to bus no.10 as voltage controlled or PV buses and bus no.11 to bus no.28 as PQ (load) buses as shown in table 1 and figure 2 respectively. The continuation power flow method uses the conventional NewtonRaphson method at the base case where $\lambda=\lambda_{0}=0$ to compute the base power load data. The slack generator of bus no. 1 is selected as the reference or swing bus, and the phase angle and angular speed of all other generators with buses numbered from 2 to 10 with respect to the reference machine are plotted against different clearing time of $(0.6,0.7,0.8,0.8150 .9)$ seconds. The solution is carried out for two swings to show that the second swing is not greater than the first one. If the angle differences do not increase, the network is stable. If any of the angle differences increase indefinitely, the network is unstable.

The PSAT program developed for transient stability analysis of a 10 generators, 28-bus Nigeria power network is subjected to a balanced three-phase fault. The program is preceded by the conventional Newton-Raphson power flow program. The input data for the conventional power flow analysis and continuation 
power flow method includes: machine data, bus data and line data are shown in tables 2 to 4 respectively. The machine phase angles, angular speed and plots of the swing curves with respect to the slack bus no.1 (Egbin PS) for 10 generators, 28-bus Nigeria power network are obtained as shown in figures 5 to 13 respectively. MATLAB/SIMULINK circuit designed using electrical blocks contained in the SIMULINK library for 10 generators, 28-bus Nigeria power network transient stability analysis is shown in figure 3 .

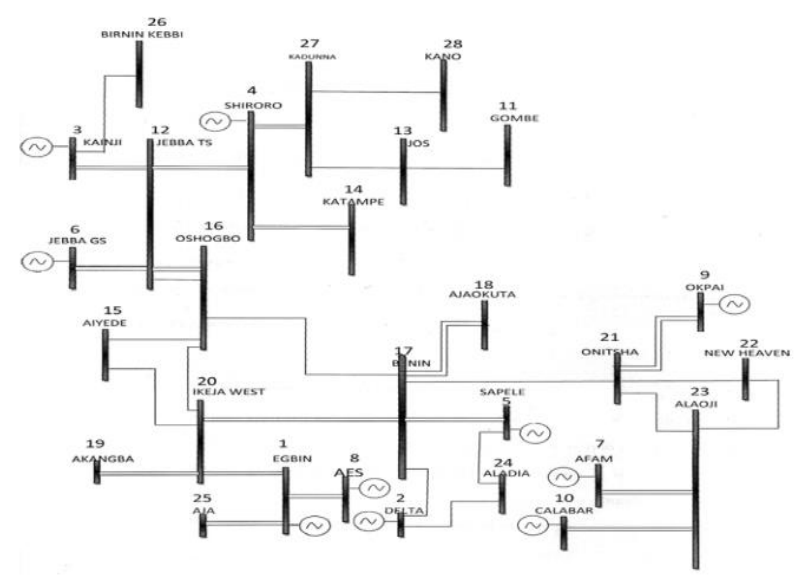

Fig. 2: One-line diagram of the existing 28 bus $330 \mathrm{kV}$ Nigerian transmission grid.

The list of the constituent buses of the existing 28-bus 330KV Nigeria transmission grid is shown in table 1.

Table 1: Bus identification for existing 330kV Nigeria transmission grid

\begin{tabular}{|l|l|l|l|}
\hline S/N & Bus name & S/N & Bus name \\
\hline 1 & Egbin PS & 15 & Aiyede \\
\hline 2 & Delta PS & 16 & Oshogbo \\
\hline 3 & Kainji GS & 17 & Benin \\
\hline 4 & Shiroro & 18 & Ajaokuta \\
\hline 5 & Sapele PS & 19 & Akanagba \\
\hline 6 & Jebba GS & 20 & Ikeja West \\
\hline 7 & Afam GS & 21 & Onitsha \\
\hline 8 & AES & 22 & New Heaven \\
\hline 9 & Akpai & 23 & Alaoji \\
\hline 10 & Calabar & 24 & Aladja \\
\hline 11 & Gombe & 25 & Aja \\
\hline 12 & Jebba TS & 26 & Birnin Kebbi \\
\hline 13 & Jos & 27 & Kaduna \\
\hline 14 & Katampe (Abuja) & 28 & Kano \\
\hline
\end{tabular}

Table 2: Machine data for 10 generators, 28-bus 330kv Nigeria transient stability simulation.

\begin{tabular}{|l|l|l|l|}
\hline $\begin{array}{l}\text { Generator } \\
\text { Number }\end{array}$ & $\operatorname{Ra}(\Omega)$ & $\mathrm{X}^{\mathrm{I}} \mathrm{d}(\Omega)$ & $\mathrm{H}\left(\mathrm{kgm}^{2}\right)$ \\
\hline 1 & 0.0020 & 0.0901 & 9.920 \\
\hline
\end{tabular}

\begin{tabular}{|l|l|l|l|}
\hline 2 & 0.0080 & 0.3000 & 3.390 \\
\hline 4 & 0.0240 & 0.3000 & 3.240 \\
\hline 7 & 0.0036 & 0.2200 & 4.000 \\
\hline 9 & 0.0020 & 0.1240 & 12.400 \\
\hline 10 & 0.0036 & 0.2200 & 4.000 \\
\hline
\end{tabular}

Tables 3 and 4 containing both Bus Data and Line Data of the 28bus networks used as input for the Simulation can be seen in the Appendix.

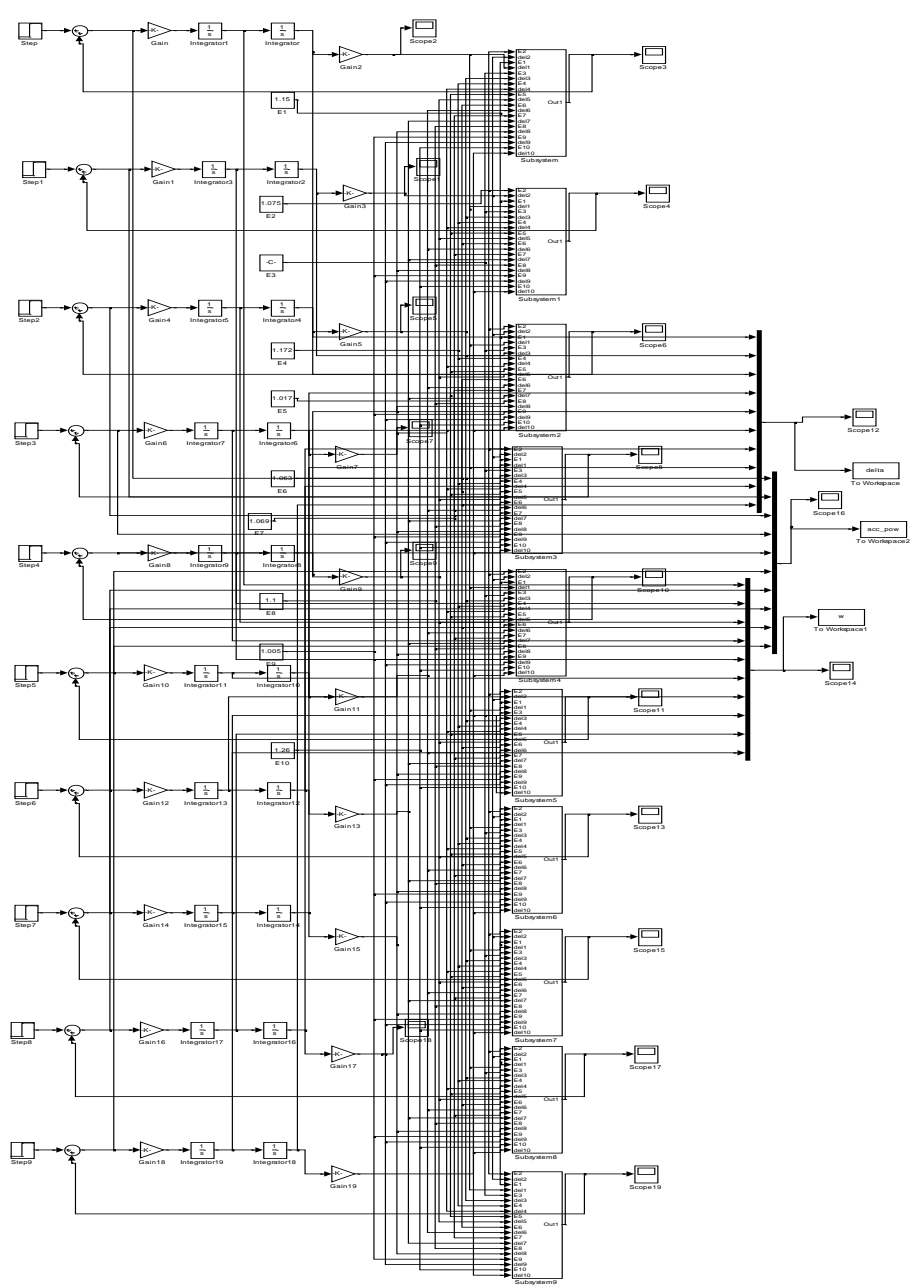

Figure 3: MATLAB/ SIMULINK circuit design for the 10 generators transient stability simulation.

\section{Results and Discussion of Simulation}

The results obtained after simulations of 10 generators, 28bus $330 \mathrm{kV}$ Nigeria power network transient stability model are presented in graphical forms. The generator phase angle, angular speeds and plots of swing curves after a balanced three-phase fault for 10 generators, 28-bus power network transient stability analysis for different fault clearing time intervals of 0.6 seconds, 
0.7 seconds, 0.8 seconds, 0.815 seconds and 0.9 seconds are presented graphically in figures 5 to 13 respectively. By observing figures 5 to 13 respectively, it is found that the generator phase angle differences decrease as 10 different generators swing together after loss of generator-connected busbar 5 (Sapele PS). A balanced three-phase fault clearing time is started at 0.00001 seconds and the Nigeria 10 generators 28-bus power network is analysed for different fault clearing time intervals ranging from 0.6 to 0.9 seconds respectively. The 10 generators, 28-bus $330 \mathrm{kV}$ Nigeria power network is found to be stable when the balanced three-phase fault occurred at generatorconnected bus-bar 5(Sapele PS) is cleared in 0.8 seconds as seen in figures 5 to 8 respectively. The transient stability result of 10 generators 28 -bus $330 \mathrm{kV}$ Nigeria power network revealed that this network is critically stable when fault is cleared in 0.815 seconds as shown in figures 9 to 10 and became unstable when fault is cleared in 0.9 seconds as seen in figures 11 to 13 respectively.

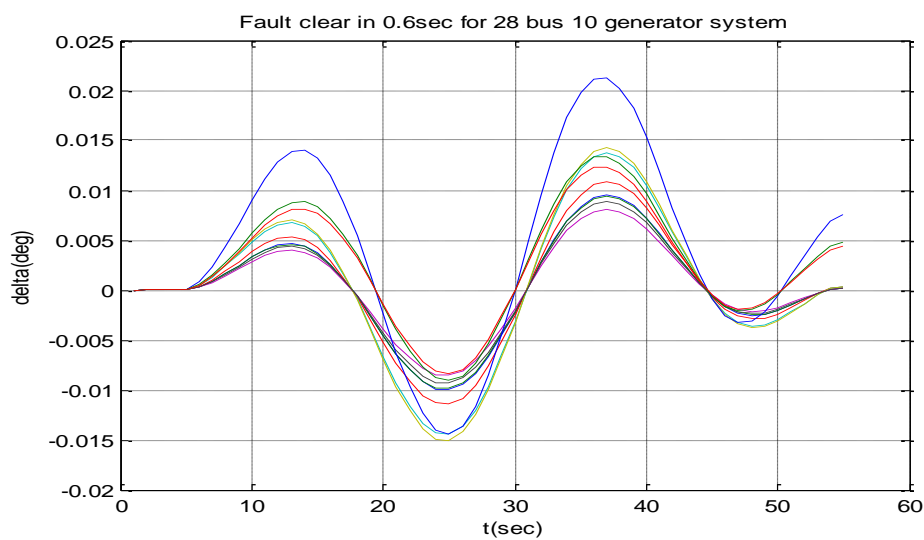

Fig. 4: Phase angle differences for 10 generators 28 bus power network at fault clearing time of 0.6 seconds.

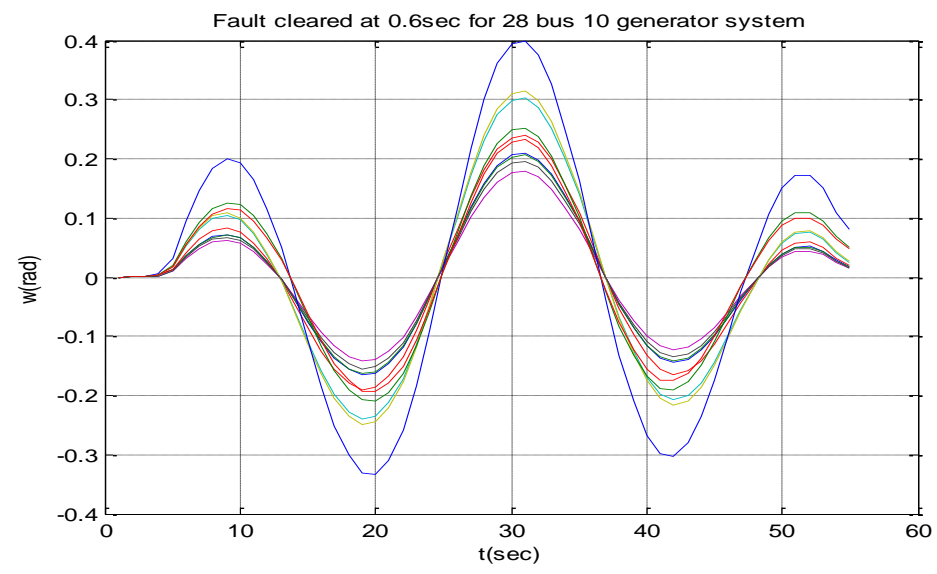

Fig. 5: Angular speed for 10 generator 28 bus power network at fault clearing time of 0.6 seconds.

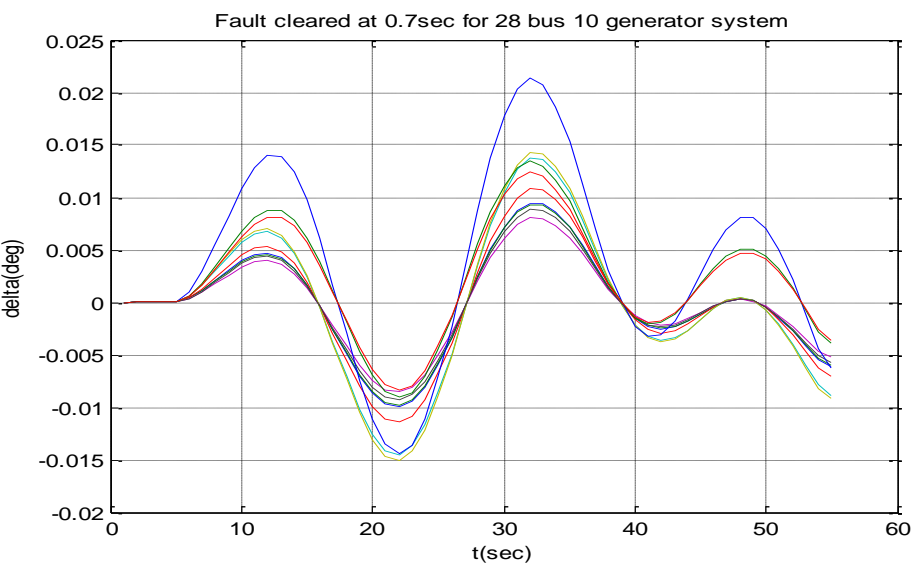

Fig. 6: Phase angle differences for 10 generators 28 bus power network at fault clearing time of 0.7 seconds.

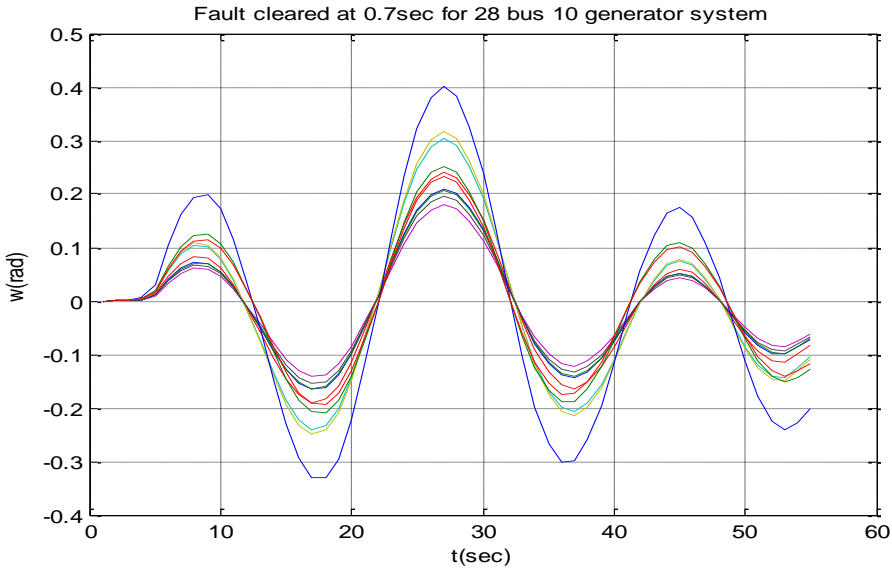

Fig. 7: Angular speed for 10 generators 28 bus power network at fault clearing time of 0.7 seconds.

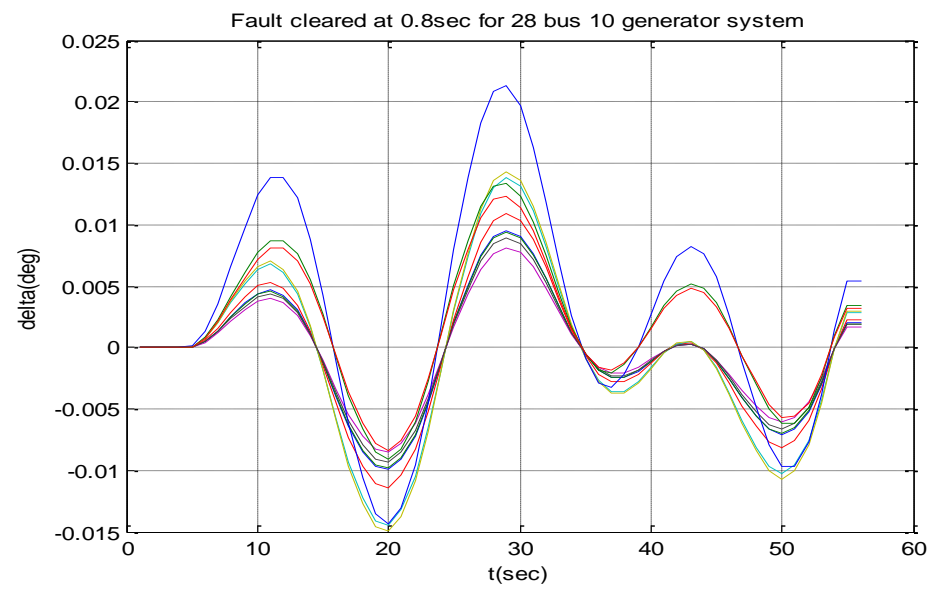

Fig. 8: Phase angle differences for 10 generators 28 bus power network at fault clearing time of 0.8 seconds. 


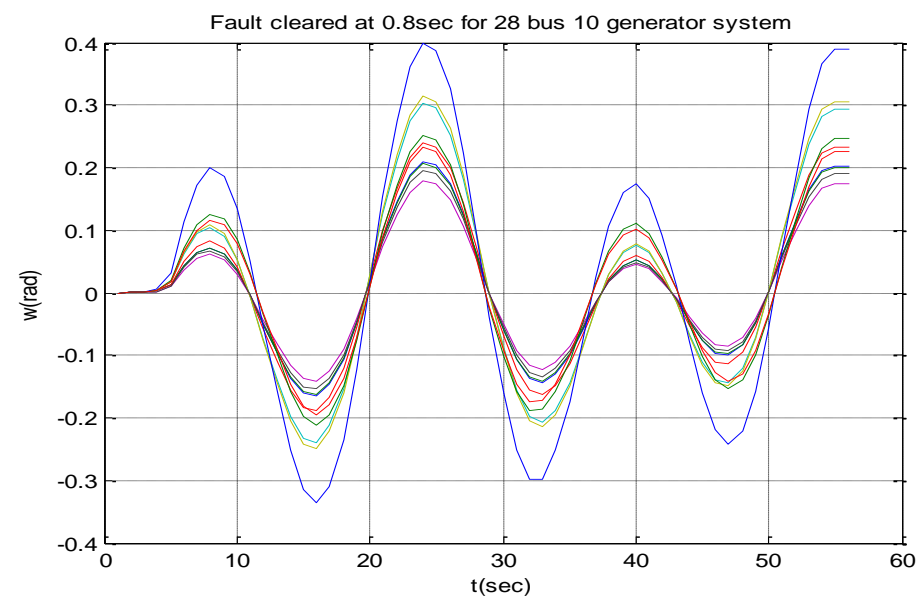

Fig. 9: Angular speed for 10 generators 28 bus power network at fault clearing time of 0.8 seconds.

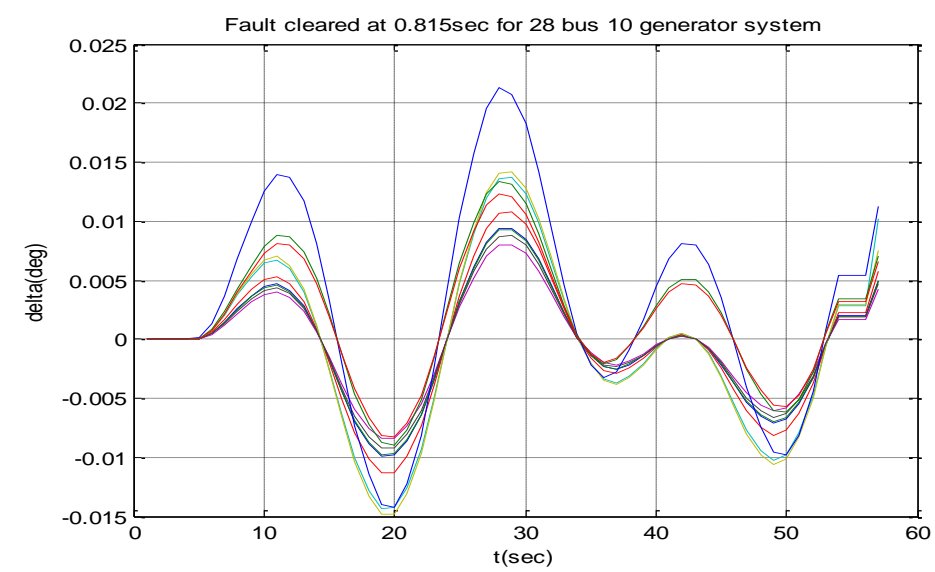

Fig. 10: Phase angle differences for 10 generators 28 bus power network at fault clearing time of 0.815 seconds.

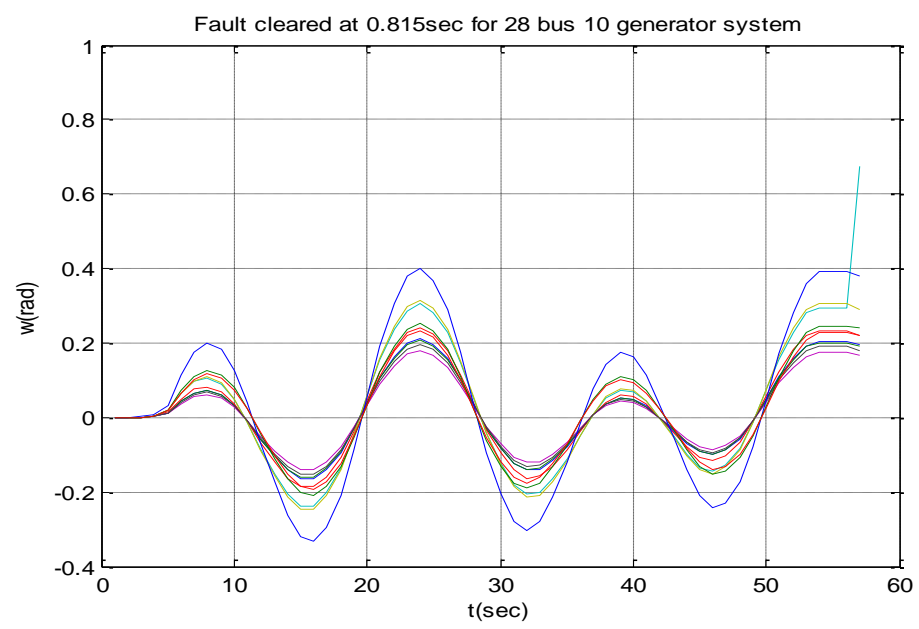

Fig. 11: Angular speed for 10 generators 28 bus power network at fault clearing time of 0.815 seconds.

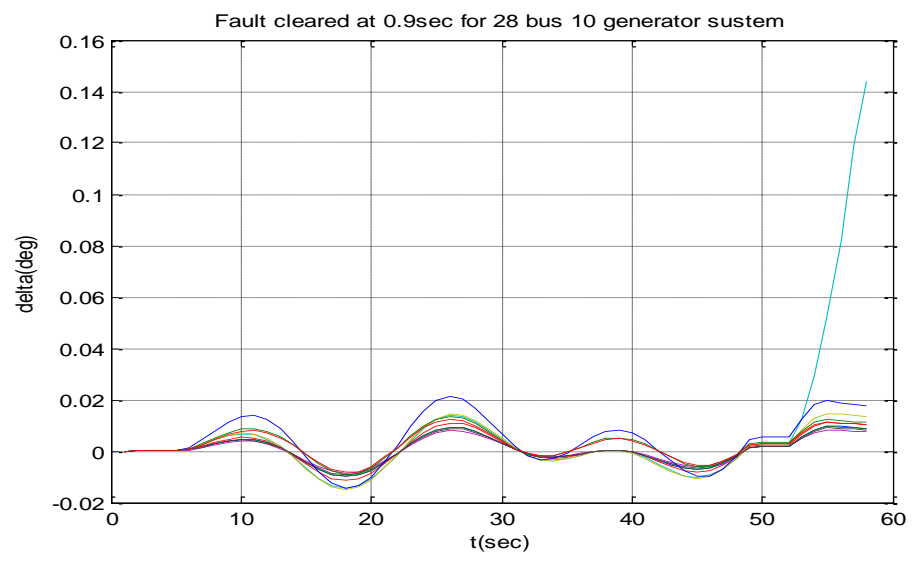

Fig. 12: Phase angle differences for 10 generators 28 bus power network at fault clearing time of 0.9 seconds.

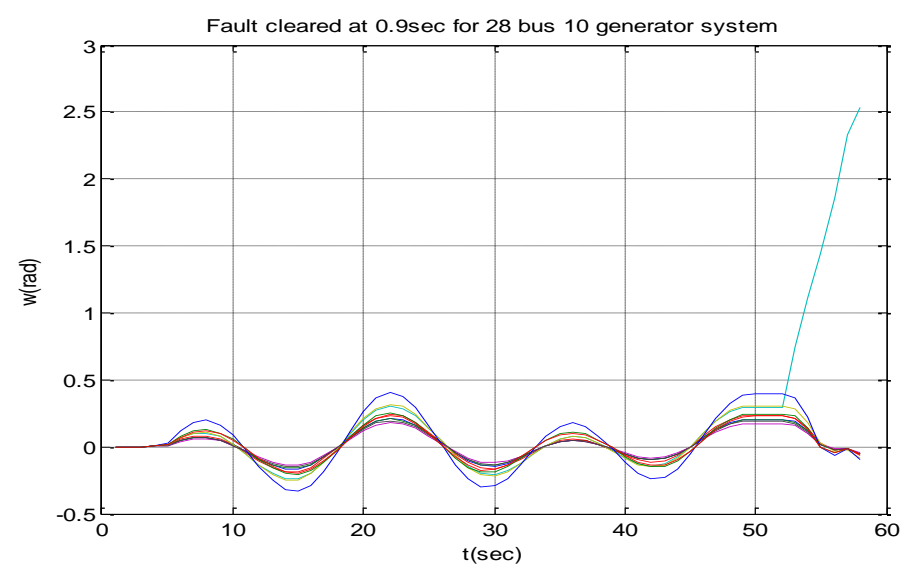

Fig. 13: Angular speed for 10 generators 28 bus power network at fault clearing time of 0.9 seconds.

\section{Conclusion}

The power system transient stability problems are briefly discussed and formulated. Transient stability analysis model of 10 generators, 28-bus $330 \mathrm{kV}$ Nigeria power network is formulated, developed and implemented using MATLAB/SIMULINK Power System Analysis Toolbox (PSAT) program and the results obtained thereafter are presented graphically.

Through the transient stability study of 10 generators, 28bus $330 \mathrm{kV}$ Nigeria power network, the synchronous generator power angles and speed deviations, real and reactive power flows of the machines, voltage levels of the buses in this power network, power flows of lines and transformers, as well as the system electrical frequency are evaluated.

The transient stability analysis performed for 10 generators, 28-bus power network for various 3-phase fault locations and 3phase fault clearing time showed that the network is stable in 0.80 seconds, critically stable in 0.815 seconds and unstable in 0.98 seconds. 


\section{References}

[1] P. M. Anderson and A. Fouad, Power System Control and Stability, $1^{\text {st }}$ edition, the Iowa State University Press, Ames Iowa, USA, pp. 1-11, 1977.

[2] A. Jha, L. Ralte, A. Kumar and P. R. Pati, Transient Stability Analysis Using Equal Area Criterion Using Simulink Model, Department of Electrical Engineering National Institute of Technology Rourkela, 2008-9.

[3] P. Basu and A. Harichandan, Power System Stability Studies Using MATLAB, National Institute of Technology Rourkela-769008, Orissa.

[4] R. Kavitha, "Transient stability of IEEE-30 bus system using E-TAP software" International Journal for Scientific and Engineering Research, 3(12), 767-775, 2012.

[5] P. K. Iyambo and R. Tzonova, Transient Stability Analysis of the IEEE 14BUS Electrical Power System, IEEE Conference, 2007.

[6] Hadi Saadat, Power System Analysis, $8^{\text {th }}$ edition, Tata McGraw-Hill Publishing Company Limited, New Delhi, pp. 460, 511-526, 2002.

[7] I. J. Nagrath and D. P Kothari, Power System Engineering, 12 edition, Tata McGraw-HILL Publishing Company Limited, New Delhi, pp. 489-490, 2002.

[8] L. Wang, L. Li, S. Shanshan, Z. Yiwli, L. Zongxiang, Z. Junliang, G. Eason and B. Noble, Stability and Security Assessment for an Industrial Electric Grid with Enterprise-Owned Power Plants, DRPT 2008, 6-9, April 2008, Nanjing China, 1563.

[9] S. Gupta and S. Prakash, "Evaluation of first swing stability of a large power system with various FACTS devices" International Journal of Engineering, Research and Technology 2(5), 294-301, 2013.

[10] O. I. Okoro, Introduction to MATLAB/SIMULINK for Engineers and Scientists, John Jacob's Classic Publishers Ltd, Enugu, pp. 20-40, 2005.

[11] Homepage of PSAT. [Online]. Available: http://www3.uclm.es/profesorado/federico.milano/psat.htm. [Accessed: 24 November, 2007]. 


\section{Appendix}

Table 3: Bus Data of the 28-bus networks used as input for the Simulation.

\begin{tabular}{|c|c|c|c|c|c|c|c|c|c|c|}
\hline \multirow{2}{*}{$\begin{array}{l}\text { Bus } \\
\text { No. }\end{array}$} & \multirow{2}{*}{$\begin{array}{l}\text { Bus } \\
\text { Code }\end{array}$} & \multirow{2}{*}{$\begin{array}{l}\text { Bus } \\
\text { Voltage } \\
\left(\mathrm{V}_{\mathrm{sp}}\right)\end{array}$} & \multirow{2}{*}{$\begin{array}{l}\text { Phase } \\
\text { Voltage } \\
\left(\theta^{\circ}\right)\end{array}$} & \multicolumn{2}{|c|}{ Load } & \multicolumn{4}{|c|}{ Generation } & \multirow{2}{*}{$\begin{array}{l}\text { Tap } \\
\text { Setting }\end{array}$} \\
\hline & & & & $\mathrm{P}_{\mathrm{Li}}$ & $\mathrm{Q}_{\mathrm{Li}}$ & $\mathrm{P}_{\mathrm{Gi}}$ & $\mathrm{Q}_{\mathrm{Gi}}$ & $\mathrm{Q}_{\min }$ & $\mathrm{Q}_{\max }$ & \\
\hline 1 & 1 & 1 & 0 & 150 & 105.62 & 0 & 0 & -200 & 200 & 1 \\
\hline 2 & 2 & 1 & 0 & 200 & 300 & 882 & 0 & -300 & 320 & 1 \\
\hline 3 & 2 & 1 & 0 & 0 & 0 & 760 & 0 & -210 & 222 & 1 \\
\hline 4 & 2 & 1 & 0 & 0 & 0 & 600 & 0 & -120 & 140 & 1 \\
\hline 5 & 2 & 1 & 0 & 0 & 0 & 1020 & 0 & -250 & 260 & 1 \\
\hline 6 & 2 & 1 & 0 & 0 & 0 & 578 & 0 & -200 & 210 & 1 \\
\hline 7 & 2 & 1 & 0 & 0 & 0 & 931.6 & 0 & -290 & 300 & 1 \\
\hline 8 & 2 & 1 & 0 & 0 & 0 & 302 & 0 & -100 & 110 & 1 \\
\hline 9 & 2 & 1 & 0 & 0 & 0 & 480 & 0 & -200 & 210 & 1 \\
\hline 10 & 2 & 1 & 0 & 0 & 0 & 600 & 0 & -120 & 140 & 1 \\
\hline 11 & 3 & 1 & 0 & 0 & 0 & 0 & 0 & 0 & 0 & 1 \\
\hline 12 & 3 & 1 & 0 & 130 & 80 & 0 & 0 & 0 & 0 & 1 \\
\hline 13 & 3 & 1 & 0 & 220 & 154.8 & 0 & 0 & 0 & 0 & 1 \\
\hline 14 & 3 & 1 & 0 & 114 & 90 & 0 & 0 & 0 & 0 & 1 \\
\hline 15 & 3 & 1 & 0 & 110 & 80 & 0 & 0 & 0 & 0 & 1 \\
\hline 16 & 3 & 1 & 0 & 104 & 70 & 0 & 0 & 0 & 0 & 1 \\
\hline 17 & 3 & 1 & 0 & 36 & 25 & 0 & 0 & 0 & 0 & 1 \\
\hline 18 & 3 & 1 & 0 & 72 & 45 & 0 & 0 & 0 & 0 & 1 \\
\hline 19 & 3 & 1 & 0 & 136 & 84 & 0 & 0 & 0 & 0 & 1 \\
\hline 20 & 3 & 1 & 0 & 72 & 45 & 0 & 0 & 0 & 0 & 1 \\
\hline 21 & 3 & 1 & 0 & 39 & 27.8 & 0 & 0 & 0 & 0 & 1 \\
\hline 22 & 3 & 1 & 0 & 84 & 50 & 0 & 0 & 0 & 0 & 1 \\
\hline 23 & 3 & 1 & 0 & 146 & 84.5 & 0 & 0 & 0 & 0 & 1 \\
\hline 24 & 3 & 1 & 0 & 32 & 17.8 & 0 & 0 & 0 & 0 & 1 \\
\hline 25 & 3 & 1 & 0 & 110 & 80 & 0 & 0 & 0 & 0 & 1 \\
\hline 26 & 3 & 1 & 0 & 100 & 58.4 & 0 & 0 & 0 & 0 & 1 \\
\hline 27 & 3 & 1 & 0 & 80 & 49.6 & 0 & 0 & 0 & 0 & 1 \\
\hline 28 & 3 & 1 & 0 & 26 & 15.3 & 0 & 0 & 0 & 0 & 1 \\
\hline
\end{tabular}


Table 4: Line Data of the 28-bus networks used as input for the Simulation

\begin{tabular}{|c|c|c|c|c|c|}
\hline \multirow{2}{*}{$\mathrm{S} / \mathrm{N}$} & \multicolumn{2}{|c|}{ Transmission line } & \multicolumn{2}{|c|}{ Line Impedance } & \multirow{2}{*}{$1 / 2 \mathrm{~B}(\mathrm{pu})$} \\
\hline & From Bus & To Bus & $\mathrm{R}(\mathrm{pu})$ & $\mathrm{X}(\mathrm{pu})$ & \\
\hline 1 & 1 & 8 & 0.0001 & 0.0004 & 0.0996 \\
\hline 2 & 1 & 20 & 0.0004 & 0.0029 & 0.0771 \\
\hline 3 & 1 & 25 & 0.0007 & 0.0057 & 0.0771 \\
\hline 4 & 3 & 17 & 0.0008 & 0.0063 & 0.3585 \\
\hline 5 & 2 & 24 & 0.0008 & 0.0063 & 0.3585 \\
\hline 6 & 3 & 26 & 0.0041 & 0.0304 & 1.8135 \\
\hline 7 & 3 & 12 & 0.001 & 0.0082 & 0924 \\
\hline 8 & 4 & 27 & 0.0011 & 0.0097 & 0.546 \\
\hline 9 & 4 & 12 & 0.0022 & 0.0234 & 1.3905 \\
\hline 10 & 4 & 14 & 0.009 & 0.0067 & 1.7933 \\
\hline 11 & 5 & 17 & 0.0002 & 0.0015 & 0.936 \\
\hline 12 & 5 & 24 & 0.0008 & 0.0063 & 0.3585 \\
\hline 13 & 6 & 12 & 0.0001 & 0.0004 & 0.0996 \\
\hline 14 & 7 & 23 & 0.0015 & 0.0012 & 0.312 \\
\hline 15 & 9 & 21 & 0.0008 & 0.0063 & 0.3585 \\
\hline 16 & 10 & 23 & 0.0163 & 0.014 & 0.786 \\
\hline 17 & 11 & 13 & 0.0032 & 0.0027 & 1.515 \\
\hline 18 & 12 & 16 & 0.0019 & 0.0159 & 0.8955 \\
\hline 19 & 13 & 27 & 0.0027 & 0.0202 & 1.2114 \\
\hline 20 & 15 & 16 & 0.0013 & 0.01 & 0.5999 \\
\hline 21 & 15 & 20 & 0.0016 & 0.0134 & 0.8057 \\
\hline 22 & 16 & 17 & 0.003 & 0.0254 & 1.431 \\
\hline 23 & 16 & 20 & 0.0033 & 0.0227 & 1.4819 \\
\hline 24 & 17 & 18 & 0.0023 & 0.0198 & 1.1117 \\
\hline 25 & 17 & 20 & 0.0034 & 0.0016 & 1.7015 \\
\hline 26 & 17 & 21 & 0.0016 & 0.0139 & 0.781 \\
\hline 27 & 19 & 20 & 0.0007 & 0.0057 & 0.3855 \\
\hline 28 & 21 & 22 & 0.0011 & 0.0097 & 0.5475 \\
\hline 29 & 21 & 23 & 0.0163 & 0.014 & 0.786 \\
\hline 30 & 22 & 23 & 0.0023 & 0.0171 & 1.3905 \\
\hline 31 & 27 & 28 & 0.0027 & 0.0202 & 1.2114 \\
\hline
\end{tabular}

